\title{
DOENÇA DE PARKINSON NO PARANÁ E RIO GRANDE DO SUL INCIDÊNCIA SOBRE INTERNAÇÕES
}

\author{
PARKINSON'S DISEASE IN PARANÁ AND RIO GRANDE DO SUL \\ INCIDENCE ON HOSPITALIZATIONS
}

\begin{abstract}
Rebecca Carolina Sanches Rodrigues ${ }^{1 *}$, Jéssica Almeida Dall' Asta ${ }^{1}$, Emanoelle Aparecida Palangani ${ }^{1}$, Aléxia Fernandes Jasinski ${ }^{1}$, Leticia Teixeira Pinheiro Guerra ${ }^{1}$, Gustavo Bacelar Peraro².
\end{abstract}

${ }^{1}$ UNINGÁ - Centro Universitário Ingá, Maringá, PR, Brasil.

${ }^{2}$ Pontifícia Universidade Católica do Paraná, Curitiba, PR, Brasil.

*rebecca.csr@hotmail.com

\section{RESUMO}

A Doença de Parkinson (DP), é uma afecção neurodegenerativa progressiva caracterizada por sintomas motores (rigidez; bradicinina; tremor de repouso, sendo o mais conhecido; e instabilidade postural), se apresentando como a segunda doença degenerativa mais comum. Manifesta uma etiologia idiopática, porém acredita-se na importância de certos fatores ambientais e sociais e a sua interação com outras variáveis, como genes, níveis hormonais ou exposições ambientais. Sua cura ainda não foi encontrada, portanto todos os tratamentos existentes visam o controle dos sintomas com o objetivo de manter o portador com o máximo de autonomia possível, para uma melhor qualidade de vida. $O$ controle dos sintomas da doença de Parkinson se faz através do tratamento farmacológico ou cirúrgico. A idade mais avançada, o género masculino, comorbilidades, o atingimento motor axial, a deterioração cognitiva e disfunção autonómica precoces têm sido apontados como fatores preditores independentes de pior prognóstico. Esse estudo objetiva promover uma análise comparativa entre o estado do Paraná e Rio Grande do Sul sobre os índices de internações por Doença de Parkinson entre o intervalo de 2014 a 2019 correspondente à faixa etária de 70 a 79 e a faixa de 80 e mais. Coleta e análise de dados do DATASUS, recorrendo ao intervalo de tempo entre 2014 a 2019. Como critério de inclusão houve análise dos conteúdos de internação da doença de Parkinson, entre os estados Paraná e Rio Grande do Sul, sobre a faixa etária de 70 a 79 e 80 e mais, assim como, analise da predominância do sexo em cada estado. Calculo realizado de forma extrema. Ao levar em consideração o número de internações associadas a doença de Parkinson, comparando o estado do Rio Grande do Sul (RS) e do Paraná (PR) levando em consideração os sexos masculino e feminino. Na fixa etária entre 70 a 79 anos no PR o sexo masculino entre os anos de 2014 (9) e 2019 (13) aumentou em 44,44\%, já no RS entre 2014 (21) e 2019 (21) não houve alteração percentual. Quanto ao sexo feminino no PR entre os anos de 2014 (11) e 2019 (5) houve redução de 54,54\%, já no RS entre 2014 (20) e 2019 (24) verificou-se aumento de $20,00 \%$. Na faixa etária de 80 anos e mais, no PR o sexo masculino entre 0 período de 2014 (3) e 2019 (2) reduziu em 33,33\%, e no RS entre 2014 (14) e 2019 (10) a redução foi de $28,57 \%$. Em relação ao sexo feminino, no PR entre os anos de 2014 (2) e 2019 (5) deu-se aumento de 150,00\% e no RS também 
entre 2014 (15) e 2019 (19) o aumento foi de 26,67\%. Conclui-se que em comparação ao sexo masculino entre 70 a 79 anos a doença de Parkinson apresentou aumento no estado do PR, enquanto no RS não houve alteração. Já o feminino reduziu a incidência no PR, aumentando no RG. Enquanto nos pacientes acima de 80 anos no sexo masculino verificou-se redução em ambos os estados, já o feminino aumento tanto no PR, quando no RS. Assim, se trata de uma doença mais prevalente acima de 80 anos.

Palavras-chave: Doença crônica. Doença de Parkinson. Doenças neurodegenerativas. Hospitalização. Incidência. 